\title{
HAROLD BLOOM: EL ÚLTIMO CABALISTA
}

\author{
Cristina ÁLVAREZ DE MORALES MERCADO \\ Universidad de Granada
}

\author{
Pues así fue: Abraham oyó mi voz y \\ guardó mi palabra, mi deseo, mis leyes, mi \\ camino.
}

L a presencia de lo judío en la obra de Bloom sigue siendo posiblemente una de las facetas más desconocidas del crítico de Yale. Sin embargo, la influencia de la tradición judía se remonta a sus primeros trabajos teóricos sobre los poetas del Romanticismo inglés, trabajos con los sugerentes títulos de Shelley's Mythmaking (1959) o Blake's Apocalypse (1963), y sigue estando presente en sus trabajos más recientes y maduros como The American Religion (2009) o The Anatomy of Influence. Literature as a Way of Life (2011). Hay tres aspectos esenciales que conforman la teoría cabalística del crítico norteamericano: el primero de ellos es la Cábala, a cuya ciencia y conocimiento dedica Bloom uno de sus primeros trabajos, Kabbalah and Criticism (1975). El segundo elemento vendría determinado por el estudio del polémico The book of J (1991) que tantas ampollas levantó en su momento entre los sectores judíos y cristianos más ortodoxos. Y, el tercero vendría a ser una aproximación a la obra de dos judíos universales, Freud y Kafka ${ }^{1}$ que, sin lugar a dudas, han marcado y definido la esencia de Bloom de una manera decisiva y, yo diría que casi vital, pues esa ansiedad del crítico de Yale por recobrar a los precursores judíos, conocedores de los principales elementos de su tradición, forma parte de su particular visión de la literatura y de la realidad. Ejemplo de ello son títulos tan imprescindibles como Agon. Towards a Theory of Revisionism (1982), Ruin the Sacred Truths. Poetry and Belieffrom the Bible to the Present (1989) o The Western Canon (1994), por citar algunos de los más interesantes para nuestro estudio.

Harold Bloom fue educado para ser talmudista, y la Cábala fue desde sus comienzos como teórico uno de los pilares que sirvió para sustentar su siempre polémica teoría literaria. Bloom ha venido abordando siempre el estudio de la Cábala a partir de las interpretaciones que el cabalista Gershom Scholem hiciera de la misma. Este autor defendía una postura historicista de la tradición cabalística. De hecho, la Cábala era, en palabras de Scholem, «lo dado», «la tradición» (Scholem, 1988: 1). En este mismo sentido es en el que Bloom plantea su teoría cabalística de la revisión, derivada

\footnotetext{
${ }^{1}$ Freud y Kafka han sido los dos autores que más han influido en buena parte de la obra bloomeana, y acerca de cuyas obras ha realizado Bloom interesantes análisis en muchos de sus libros: A Map of Misreading, Kabbalah and Criticism, The Breaking of the Vessels, The American Religion o The Western Canon, entre otros.
} 
de una dialéctica entre las tendencias más heréticas de la Cábala, el Gnosticismo, y la aceptación cabalística del Libro Fundador. Aunque el propio Bloom limita su actividad a la de un comentador de los textos poéticos/proféticos que él considera «fuertes», sin embargo, al final de su obra consigue edificar con un vocabulario adecuado toda su magistral teoría del «constructor poético». Harold Bloom dice que la Cábala entre los hebreos quiere decir recepción: «aprender a estimar y reverenciar a los sujetos antiguos», ideal que recogió el propio Gershom Scholem, convirtiéndose, en palabras de Bloom, en uno de los ejemplos más abrumadores del escritor capaz de realizar esa «mala lectura» del conjunto de la Cábala (Bloom, 1975a: 4). Aún más, Bloom asegura que podemos necesitar varias generaciones antes de que otro punto de vista de la Cábala exista para nosotros, pues: «Él ha realizado una mala-lectura tan fuerte de lo que él llama el gnosticismo judío, lo que es por supuesto un oxímoron. Simplemente diría que estoy más bajo el impacto de Scholem que Borges o Derrida» (Cañeque, 1984: 57). Scholem es para el crítico de Yale casi una figura miltónica. Él aseguraba que la Cábala contribuyó a la comprensión de la psicología histórica del judaísmo. De hecho, los cabalistas intentaron descubrir el misterio del mundo como un reflejo de la existencia divina misma: «sus imágenes, en las que se condensaban sus experiencias, se hallaban en estrecha relación con las experiencias históricas del pueblo judío, es decir, con experiencias que en el siglo XIX parecían haber perdido su actualidad» (Scholem, 1988: 1-2). Para Scholem, igual que para Bloom, todos los textos cabalísticos son interpretativos o especulativos, y lo que interpretan es un texto central que posee autoridad y que puede ser tomado como un texto en sí mismo: «el Zohar o Libro del Esplendor, de finales del siglo XIII y que se ha considerado con el rango de texto sagrado» (Scholem, 1988: 4). Para entender los elementos que lo conforman hay que estudiar no sólo la crítica de su redacción, sino también la historia de la tradición en la que éste está inscrito, así como las fuentes de su crítica y la forma que ésta adopta (Bokser, 1980: 47-48).

No olvidemos que la Cábala, esta nativa tradición hebrea, fue dada en el año 586 a.C. al escriba babilónico Ezra, para el que la destrucción del Primer Templo y el exilio fueron acontecimientos que traumatizaron su memoria cultural y personal. Alarmado por el crecimiento de la relajación moral y el fácil contacto con el mundo pagano - casi una ansiedad de profanación-, Ezra incitó a los judíos a renovar su convenio con el Libro ${ }^{2}$. Pero no será hasta que se lleve a cabo la «reconstrucción del Templo», cuando Israel llegue a ser la nación del Libro, en cuyo seno se constituyó la Torá (Álvarez de Morales, 1996: 41). Por otra parte, durante el período greco-latino, el judaísmo rabínico creó un nuevo comentario conocido como Mishnah. La Mishnah es una estructura textual que supone la presentación de las interpretaciones de dos $\operatorname{Sagas}^{3}$ :

\footnotetext{
${ }^{2}$ El Libro es para los judíos la Torá.

${ }^{3}$ Por «Sagas» entendemos en este contexto la definición que nos ofrece el D.R.A.E. y que dice así: son relatos novelescos que abarcan las vicisitudes de dos o más generaciones de una familia.
} 
1. La primera Saga es la que se refiere a la Halakah, que está determinada por las sagas que conforman la base de la tradición escrita y oral y establece precisamente cómo debe observarse la ley.

2. Y, la segunda Saga es la que se refiere a la Haggadah que, por el contrario, trata de la creencia más que de la práctica.

Recordemos, en este sentido, que en el Talmud de Babilonia y de Palestina, por ejemplo, la discusión entre ambas, Haggadah y Halakah, seguía situada dentro de una forma textual y lingüística fijada que respondía a la siguiente estructura:

a) La presentación de la ley religiosa se entendía como la Mishnah.

b) La discusión de la ley propiamente dicha era la Halakah, a pesar de los desacuerdos entre las Sagas y los pocos conceptos básicos de una naturaleza legal y de una forma común a todas ellas para conformar la Ley.

c) Una historia haggadahica en la que el héroe rellena la ley religiosa de acuerdo con su entendimiento personal y contrario a las prescripciones de las Sagas tal y como se encuentran en la empresa Halakah.

d) Y, finalmente, las reacciones de las Sagas a la Historia, indicando su opinión de los acercamientos de la Halakah y la Haggadah para completar la Ley (Lapidus 1993: 100-102).

Las Sagas expresaban pues una enorme variedad de opiniones ${ }^{4}$.

Después de Ezra fue Rabi Hillel (70 a. C.-10 d. C.) quien reorganizó el conjunto de discursos e interpretaciones acumuladas hasta entonces, y desarrolló plenamente el aspecto de la ley oral, la Mishnah, que es distinta de la Midrash ${ }^{5}$ porque es un discurso que no está atado a la escritura. Además, la lectura midráshica (que podría ser perfectamente el tipo de lectura defendido por Bloom en toda su producción crítica) puede definirse como una exégesis por su intertextualidad radicalmente explícita. Por ello, si la Midrash es una interpretación, será porque muestra cómo el significado es creado en las casi infinitas relaciones dialógicas de un texto con la Torá y el discurso de los lectores de ese texto con los otros (Boyarin, 1987: 547).

En la misma línea de Hillel, el rabino Akiba continuó con la tarea de luchar contra la opresión cristiana, a la que se vio sometido todo el pueblo judío ante el surgimiento del cristianismo. Pero hasta el siglo XII no se lleva a cabo una revisión de la literatura rabínica reinterpretada por Maimónides,

\footnotetext{
${ }^{4}$ En el caso de que una ley sea infringida en público estas estructuras fijadas siempre tendrían valor. Sin embargo, en caso de un peligro mortal, un judío podía romper las leyes de la Torá, incluyendo aquellas conectadas indirectamente con la idolatría, con la excepción de una idolatría explícita de incesto y de asesinato.

${ }^{5}$ La Torá oral significa la Torá expuesta oralmente en el proceso interactivo de una lectura dialéctica de la ley. El significado no está en el Cielo, ni es tampoco una voz que se escucha detrás del texto, sino que está en la propia Midrash, en las voces que están justo enfrente del texto. «La Torá escrita es la Torá que está escrita y la Torá oral es la Torá que es leída» (Boyarin, 1987: 545).
} 
según los principios aristotélicos. Es entonces cuando se comienza a asentar la Biblia que sirve para recordar al creyente su anterior conocimiento de Dios, a la vez que se orienta al no creyente. Sin embargo, sus signos son inadecuados todavía a la intensiva realidad divina, que solo se conocerá a través de la vida en la fe.

Tiempo después y hasta la llegada del Cristianismo no se realiza la fijación de los códigos rabínicos. Se trata entonces de una revisión de los misterios talmúdicos y de unas piadosas tendencias judías que encontraron exposición directa en el movimiento cabalístico: «Los místicos desarrollaron su esoterismo en el mismo centro del judaísmo rabínico» (Ash, 1987: 69). De hecho, los cabalistas pretendieron en todo momento establecer el significado literal de la Torá, a pesar de abogar por la innovación de la tradición, buscando una nueva y original exposición adecuada a sus deseos.

Durante la Edad Media, se produce la diáspora judía, y los místicos como Isaac Luria, fundador ya en Palestina de la Cábala zohárica, vuelven a establecerse dentro de la tradición rabínica judía que consideró el Libro como «una entidad independiente entre el hombre y Dios». De este modo se nos recuerda que la sabiduría no es algo «secreto» sino referido a los principios normales de exposición. La Cábala ya no es simplemente una herejía de reorganización, «la antitética batalla contra la ortodoxia» (Bloom, 1975: 5); sino que también está movida por el deseo de usar el lenguaje a imitación de Dios, lo que no quiere decir que sea el deseo de reemplazar las palabras de Dios por las del hombre.

Bloom nos recuerda que el creador de la Cábala zohárica (la Cábala por la que él se interesa) fue Isaac Luria, también llamado ARI, que en el siglo XVI creó la Teoría Regresiva de la creación, esto es, «una revisión de la Teoría cabalística emanativa de la creación» (5). ARI fue el último gran cabalista, y entendió la Cábala como un estudio e interpretación de los llamados «tres estados»: el primer estado se llama zimzum, que es «la doctrina de la contracción», en este estado se produce la retirada del Creador del Universo, de manera que se hace posible otro tipo de creación. El segundo es el shevirath hakelim que supone para Luria la ruptura de los recipientes, esto es, nos ofrece una visión de la creación como catástrofe. Los recipientes se quebraron al recoger el flujo lumínico que provenía de las «sefirots» (figuraciones complejas de Dios) y representan una imagen zoharística de la agonía de los reyes primitivos (Scholem, 1988: 123). Y, el tercero es el tikkun o la restitución del universo, algo así como la contribución del hombre al trabajo de Dios. El tikkun es la Redención de Israel, lo que significa la redención de todas las cosas: la meta final del Universo. Los dos primeros estados están presentes en la Teoría de la deconstrucción, desde Nietzsche y Freud hasta los actuales exégetas representados claramente en nombres de la talla de Paul de Man, quien interpreta la lectura subjetiva como el nuevo ser mítico, y entiende que el nuevo lector es una especie de superhombre, pues se trata de un lector que está a la vez ciego y atento a la luz, semi-deconstruido y conocedor del dolor que causa la separación del texto y de la naturaleza, y que está, sin duda, más receptivo a una labor revisionista de la buena poesía que nos queda por recibir (Bloom, 1975: 5). El tercero quedaría recogido en parte en la teoría bloomena de las seis ratios revisionistas. Como todos sabemos la Teoría luriánica de los tres estados ha servido a Harold Bloom para concebir su interesante, pero como siempre polémica, teoría poética de sus seis ratios revisionistas. Las seis ratios son presentadas por su 
autor como seis formas de mala lectura de los textos poéticos, seis maneras de tergiversar y mal interpretar los textos precursores de la tradición religiosa y poética. Para Bloom, como nuestros lectores recordarán, el «poeta fuerte» es una especie de profeta moderno capaz de crear su propio poema fuerte tras un largo proceso de purgación, peregrinación, solipsismo, caída al abismo y recuperación, que lo convierten en un escritor tan fuerte como lo fuera su padre poético, ese precursor que lo elige y en el que influye de forma tan poderosa.

Desde la Edad Media hasta principios del siglo XIX en la Europa más occidental, el estudioso más serio de la Cábala fue Franz Josef Molitor, un cristiano influido enormemente por el romanticismo místico de Franz von Baader. En el Este de Europa, sin embargo, donde los judíos estaban mucho menos sujetos a las presiones de la asimilación a partir de la emancipación, la joven «Ciencia del judaísmo» toma una forma más nacionalista. En concreto Italia, donde la ilustración judía tomó un curso más o menos similar, con S.D. Luzzato, se hizo, sin embargo, más hostil a la Cábala y a sus contemporáneos de la Europa del Este, pues se dedicó a recordar a los suyos que solamente estableciendo una legitimidad filosófica de la Cábala el misticismo judío podría ser rescatado de su escasa comunicación.

En nuestros días, la Cábala está representada, entre otros, por la figura de Bloom, quien se proclama a sí mismo como el gran defensor del logocentrismo occidental. Asegura que lo que Derrida llamó Escena de la Escritura depende de la Escena de la Enseñanza, y claro ejemplo de ello lo tenemos en la poesía que es desde sus orígenes crucialmente pedagógica. Para Bloom la tradición literaria comienza cuando un «autor fresco» es conocedor simultáneamente no sólo de su propia lucha contra las formas y la presencia de un «precursor», sino que lucha también contra todo lo que llegó antes que él. Por tanto, para él la tradición es principalmente oral, como la Cábala, porque además de estar formada por el conjunto de todo lo dado, es la tradición que se transmite de generación en generación, como ocurría con la poesía en sus orígenes. Recordemos, sin embargo, que para Derrida «no hay nada fuera del texto», y que cuando se escribe se hace para esconderse de lo único que nos puede «vestir», la escritura, el texto, del que debemos conocer sus reglas para poder interpretarlo, porque de otra forma quedaría incomprensible para nosotros. La única manera de que el texto tenga una presencia, por tanto, es gracias a la escritura, que es el verdadero fármaco que repara y produce, acumula y remedia, aumenta el conocimiento y reduce la pérdida de memoria (Derrida, 1981).

Pues bien, si la tradición oral defiende el prestigio de los orígenes que son recreados en la tradición poética como una «fijación sobre el precursor como profesor o sabio, o sobre el padre poético como un dios mortal» (Bloom, 1973: 59), ninguno de nosotros podría escribir, enseñar o pensar o incluso leer sin imitar al «precursor», porque «lo que se imita es lo que otra persona ha hecho: la escritura, enseñanza, pensamiento o lectura de esa persona» (59). Estamos ante uno de los temas más específicamente bloomeanos, el de la «ansiedad de la influencia», que es definida por nuestro crítico como una especie de melancolía que siente el «poeta fuerte» por las palabras precursoras.

Así pues, podemos afirmar que la Cábala, al ser una tradición, opera como lo que se podría llamar un mito tácito de la continuidad: la sabiduría se asume para ser inmemorable, válida para todo tiempo 
y en todo tiempo; y, aunque las circunstancias externas puedan cambiar, se transmite como una herencia preciosa de una generación a otra, ofreciéndose como guía para las vidas que están por venir (Alter, 1994: 437).

\section{El libro de J}

La tarea fundamental a la que Bloom se pone manos a la obra en este curioso trabajo titulado $\mathrm{El}$ Libro de J, con la inestimable ayuda de David Rosenberg que nos ofrece la traducción del mismo, es la de «extraer» El Libro de $J$ de su contexto en la Torá del Redactor. Lo que vendría a ser otra reinterpretación cabalística. De hecho El Libro de $J$ queda reducido a los escritos mejores y los más profundos de la Biblia hebrea, cuya consecuencia es evidente y palpable: «lo que va a aflorar es un autor aislado, arrinconado por los moralistas y los teólogos normativos, que transitan por caminos totalmente distintos e incompatibles de los del Yahavista» (Monferrer Sala, 1998: 431). Lo que el escritor J retrata es un judaísmo arcaico, similar al que predicó el cabalista israelí Moshe Idel, quien no encontró gnosticismo alguno en la Cábala sino elementos sobrevivientes de una visión arcaica que los gnósticos habían parodiado durante siglos.

La versión de la Biblia hebrea que Harold Bloom ofrece con su Libro de $J$ es quizá una de las más polémicas pero a la vez más originales y ricas que han aparecido en los últimos tiempos. No debemos confundir la Biblia hebrea, cuyo origen es el Libro de J, con la Biblia cristiana, que se basa en aquella, pero que constituye una revisión de la Biblia de los judíos. Mientras que las Escrituras sagradas de los judíos se agrupan en la Torá, El libro de los Profetas (Nevi'im) y el de los Escritos (Kethuvim), los cristianos llaman Viejo Testamento a la Biblia hebrea porque la consideran superada por su Nuevo Testamento, obra inaceptable a su vez para los judíos (cfr. Bloom, 1995: 15).

Así pues, El Libro de $J$ ha de considerarse como el libro más antiguo de los que forman parte del Pentateuco o, mejor dicho, de la Torá si nos ceñimos al concepto judío puro. Este Libro es una especie de hilo conductor que ha unido el Génesis con el Deuteronomio, teniendo como base la referencia a Yahvé, así como otros muchos rasgos que conforman el Antiguo Testamento cristiano: «ya hablemos de la Biblia hebrea o del Viejo Testamento nos referimos a una obra cuya base es el escrito de $\mathrm{J}$ » (Bloom, 1995: 24). A lo largo de la historia se han otorgado diferentes fuentes a cada uno de estos cinco libros, y en correspondencia con ellos se les ha asignado una letra concreta. Así, por ejemplo, J representa al Yahvista, por referencia a Yahvé, que en alemán se escribe Jaweh ${ }^{6}$ :

Son todos revisiones o censuras del texto original de J, y sus autores son: E, o Elohístas, por «Elohim», nombre plural usado para Yahvé en esta versión; P, por el Autor o escuela Sacerdotal (Priest) que escribió todo el Levítico; D, por el Autor o los autores del Deuteronomio; y R, por el Redactor que llevó a cabo la revisión final del retorno del cautiverio de Babilonia (Bloom-Rosenberg, 1995: 17; la traducción es mía).

En opinión de Bloom, El libro de J pretende efectuar la restauración del más grande escritor judío. Además de descubrir que todo el conjunto de escribas y sacerdotes normativos: E, D, P, R,

\footnotetext{
${ }^{6}$ De ahí la J, porque es precisamente el alemán Rosenberg el que ofrece la traducción de la Biblia que le sirve a Bloom para establecer sus teorías sobre el escritor J.
} 
llevaron a cabo una labor encaminada al servicio a Yahvé, pero no de servicio a la Yahvista, al «genio», escritor/-a del Libro de J. De hecho, El libro de $J$ participa de todos los libros que conforman el Pentateuco, y por tanto, no se corresponde con ninguno en particular sino que se trata de una voz que resuena en todos ellos.

Basándose en la ironía del escritor y autor (-a) de este libro, Bloom crea un corpus teórico que apoya continuamente con el propio texto bíblico a partir de la traducción que el estudioso Joel Rosenberg ha hecho del mismo. El libro de $J$ traduce desde una perspectiva completamente literaria un mundo que ha estado reducido a los ámbitos ético-religiosos. Sin embargo, la versión que Bloom ofrece se sitúa en una vertiente puramente estética, pues ni el autor-traductor de la misma (Rosenberg) ni su comentarista (Bloom) han pretendido en ningún momento continuar dentro de una línea ortodoxamente religiosa. En este sentido, habría que hacer hincapié en un aspecto esencial que se va a repetir a lo largo de toda la obra de Bloom como es la defensa literaria que el crítico de Yale hace de la figura de la Yavista, a la que sitúa a la misma altura literaria de Shakespeare o de Dante. Parece ser, y así lo cree también Bloom, que el escritor del Libro de J vivió en la Corte del hijo del Rey Salomón, el rey Roboam de Judá, en torno al 900 a.C. ${ }^{7}$ Y que perteneció posiblemente a la élite de la Corte salomónica, pues la sutileza, destreza e ironía de su lenguaje y estilo demuestran que se trataba de una persona culta y refinada. Pero lo más interesante de la personalidad de J es que, -a juicio de Bloom-, este personaje es una mujer «que se dirigió como mujer a sus contemporáneos, en amistosa competición con su único rival poderoso entre sus contemporáneos: el autor masculino de la breve narración histórica del Libro II de Samuel» (21). Aunque el origen del escritor-autor de la mejor Biblia (o la que, en opinión de Bloom, es la mejor versión del Antiguo Testamento) es oscuro, sin embargo, el trabajo de Rosenberg y Bloom ayudan de forma extraordinaria a desentrañarlo. Lo más curioso de la versión bloomeana es su idea de que es una mujer, la «Yavista», la que escribió El libro de J, su verdadera voz de autoría:

Nuevamente corro el riesgo de ser acusado por los críticos feministas de ese espantoso pecado el «esencialismo», cuando sugiero que J ve el poder asentado en lo marital y familiar por la misma razón por la que no tiene héroes masculinos: porque es una mujer juiciosa (44).

Hasta ahora tanto la tradición bíblica judía como la cristiana se habían basado en el Pentateuco como la parte esencial de su idiosincrasia religiosa. Para la segunda, estos cinco libros formarían parte de su antiguo Testamento y, para la primera constituirían su Torá, su Biblia con mayúsculas. Todos estos libros fueron escritos por hombres sabios de las distintas culturas en las que se produjeron. Si nos basamos en lo que hasta ahora se ha considerado la lógica autorial, nos resultaría muy difícil pensar que ciertamente no fuera un hombre el hacedor de estos escritos, pues únicamente él tenía acceso a la lectura y, lo que es más importante en este caso, a la escritura. Pero si nos atenemos a esa «obviedad», parecería difícil aceptar la tesis de Bloom de que el autor de este Libro sea una mujer.

\footnotetext{
${ }^{7}$ Sigo la cronología cristiana, aunque no sea la ideal en opinión de Bloom, ya que estaría mejor hablar en términos de E.C., Era Común.
} 
Sin embargo, en el Libro de $J$ el número de personajes femeninos es mucho mayor que el de los personajes masculinos, aparte de que los primeros están tratados con mayor perfección y sutileza. Además (y esta sería la tesis fundamental que Bloom baraja), la ironía con la que trabaja J es tan sutil y genial que, sin lugar a dudas, sólo puede haber sido utilizada por una mujer, la mujer-escritora, la Yahvista. La ironía, como ya asegurara Northrop Frye ${ }^{8}$, es en la literatura un mito sofisticado, algo así como la frustración o la parodia de los mitos, cómicos o románticos, más primitivos, en los que se consumó con éxito una búsqueda (Frye, 1973: 80). Posiblemente el papel de la mujer en estos textos se entendería mejor si tenemos presente la importancia que se le otorga a ésta en el surgimiento de la familia como elemento vertebrador y crucial en la tradición bíblica cristiana.

Recordemos, en este sentido, unas declaraciones que Bloom hizo en la entrevista concedida a Nora Catelli en el artículo «Y una mujer creó a Dios», en las que insistía:

\begin{abstract}
Me parece a mí que todo, en el texto original del Génesis, Éxodo y Números, todo aquello que permita comparar la psicología de los personajes masculinos con la de los femeninos orienta fuertemente el texto a favor de las mujeres. No existen allí figuras masculinas satisfactoriamente, incluido el mismo Jehová, en $E l$ Libro de J. Mientras que las serias figuras femeninas que culminan en Tamar [...], son no sólo poderosas sino que además son retratos favorables [...]. No existe duda para mí, y mi libro tratará de ser suficientemente convincente en este sentido, de que J es el único (y la única) figura dentro del exiguo repertorio de creadores de lo más elevado de lo sublime occidental, que verosímilmente puede ser una mujer [...]. Es difícil remontar el cambio hasta ella debido a que el trabajo de los revisores-autores masculinos de la Biblia corrigieron y mutilaron el texto de J [...]. Pero lo que se oye es la voz de una mujer (Catelli, 1991:15).
\end{abstract}

John Barton (1990) por su parte, asegura en su artículo «It's a girl!» que, aunque parece difícil de creer que realmente fuera una mujer la que escribiera este libro, sin embargo, la idea que Bloom nos ofrece es tan intrigante que no se puede pasar por alto. En cualquier caso, si hay algo cierto en $\mathrm{El}$ Libro de $J$ de Bloom - a juicio de Barton-, es el modo en que su autor procede, esto es, «mediante una lectura atenta del texto, para establecer a J como un autor en su propio derecho, el autor más temprano y el mejor de todos los escritores hebreos» (Barton, 1990: 3). Barton está, además, de acuerdo con Bloom en que el escritor $\mathbf{J}$ es un genio y en esta genialidad se centra «la grandeza de $\mathrm{J}$ ». De hecho Bloom compara al escritor J con Shakespeare, asegurando que ambos son los pioneros en la creación de personajes de una compleja psicología «y cuyo genio no puede ser ocultado por ninguno de los géneros propios de cada cultura» (3). Por ejemplo, Yahvé sería uno de los personajes principales de J, pero no tanto por lo que representa, sino por su psicología. Recordemos que, para Bloom, Yahvé es un personaje humano que no posee la santidad o moralidad propia de su esencia, sino que es ante todo un personaje exuberante en cualquiera de los actos que realiza a lo largo del Libro. En este sentido Yahvé sería el héroe de la narración de J, si por héroe se entiende un personaje central. Aunque hay que dejar claro que en El Libro de J-en opinión de Bloom- no hay héroes sino sólo heroínas. Yahvé se muestra en muchas ocasiones como una persona normal, que incluso tiene miedo y padece los mismos temores que un ser humano. Así se confirma cuando leemos, por ejemplo, que Yahvé actúa como un tirano capaz de hacer daño al mejor de sus siervos: «¿Por qué hieres a tu siervo?, preguntó Moisés a Yahvé

${ }^{8}$ Northrop Frye es autor de culto para Harold Bloom y asume muchas de sus teorías literarias como propias. 
¿Te he ofendido tanto como para que pongas sobre mí la carga de este pueblo?» (Bloom-Rosenberg, 1995: 168).

Bloom abunda en su teoría asegurando que aunque la mayoría de los personajes del Libro de $J$ no son vistos por su autora como seres especialmente buenos y grandiosos, sin embargo, en el caso de las mujeres, la Yahvista cambia su estilo y les termina dedicando la mayor parte de los capítulos. Así pues, nos encontraremos, por ejemplo, ante el caso de Eva cuando concibió al primero de sus hijos, Caín, que se enfrentó a Dios y fue capaz de «mal interpretarlo», situándose así a su misma altura. Además él fue quien posteriormente se enfrentó a su madre, poniéndose, por tanto, más alto todavía: «Y el hombre conoció a Eva, su mujer, en la carne; ella concibió a Caín: "Como Yahvé, yo he creado un hombre", dijo ella cuando dio a luz» (Bloom-Rosenberg, 1995:75).

O en el caso de Rebeca cuya sublime aparición es descrita así en el Libro:

No había acabado de hablar, y he aquí que salió de la ciudad Rebeca, hija de Betuel -un hijo de Milca, mujer de Nacor, hermano de Abraham-, y llevaba un cántaro en el hombro. La joven era hermosa como aparición, igual de fresca, y no había conocido hombre, y bajó a la fuente (Bloom-Rosenberg, 1995: 100).

Es evidente que la sobreabundancia de mujeres en $\mathrm{J}$ y las acertadas y «femeninas» descripciones por parte de su autora, hacen de este texto un ejemplo de lo alto que se puede llegar a oír la voz femenina, como afirma el crítico Barton: «puede resultar brillante o anacrónico, yo creo que es ambos a la vez, pero no es un libro que se pueda ignorar» (Barton, 1990: 4). En el mismo sentido, Donald Davie, una destacada figura del panorama crítico literario norteamericano, comentaba en su artículo «La Biblia de Bloom», que, aunque todos nosotros encontramos frívola la idea de Bloom de que el escritor $\mathbf{J}$ sea una mujer, es porque nos acercamos a los textos sin esa necesidad vital y sin el temor necesario que su lectura provoca. Estos son, sin embargo, los motivos que Bloom encuentra imprescindibles para poder leer este tipo de textos, consiguiendo que «esta sea la lectura más atractiva y apropiada» (Davie, 1991: 11).

Si las principales críticas que El Libro de $J$ recibió se debieron a su «descabellada» idea de que la autora del mismo fuera una mujer, hay muchas otras que se le hicieron desde distintos ámbitos religiosos, principalmente cristianos y judíos, que habían visto en la obra de Bloom un atentado a sus tradiciones. En este punto no nos detendremos demasiado si tenemos en cuenta la afirmación que el mismo Bloom hace al respecto:

La tendencia o inclinación social e individual a la lectura errónea institucionalizada de $\mathrm{J}$ ha estado y está extraordinariamente extendida, tanto entre los judíos, como entre los cristianos, los musulmanes y los miembros de la cultura secular. Existen profundas razones para que no se considere la Biblia como un texto comparable con Hamlet o El Rey Lear, La Divina Comedia, La Ilíada, los poemas de Worsdworth o las novelas de Tolstoi. Evidentemente tanto creyentes como historiadores están justificados en juzgar la Biblia más comparable con el Corán o el Libro de los Mormones. Pero, ¿y si uno no es un creyente ni un historiador? (Bloom, 1990: 23).

La respuesta que Bloom da a esta última pregunta se definiría en la persona de un lector hipotético capaz de acercarse a la Biblia como un texto rico en sugerencias y abierto a la interpretación, que es como el propio Bloom lo ha hecho. De hecho, no podemos olvidar que uno de los riesgos más 
destacados del escritor $\mathrm{J}$ es su acentuada ironía al escribir y recrear a los personajes. Y es que J es un maestro de la ironía, ciertamente «su principal actitud irónica es muy diferente y debe ser considerada como de su propia invención» (37). Una de las ocasiones en las que Bloom defiende con más fervor la ironía de J, es cuando Yahvé moldea la arcilla, no como el alfarero, sino a la manera de un niño que hace tartas de barro, sin seguir ninguna regla, con su propias manos (Bloom, 1995: 40): «Yahvé modeló un hombre con arcilla de la tierra, y sopló en su nariz el aliento de la vida. Y mirad: el hombre se hace criatura de carne» (Bloom-Rosenberg, 1995: 71). A esta idea se une el hecho de que cuando Yahvé exhala su aliento, no se sabe bien si lo hace por la nariz o por la boca del ser que acaba de hacerse con arcilla roja. La imagen, en opinión de Bloom, es bastante grotesca, pero lo sería aún más si tenemos en cuenta que no existe ningún otro relato en toda la literatura del Antiguo Oriente sobre la creación de un personaje femenino: «Que J dedique seis veces más espacio a la creación de la mujer que a la del hombre tal vez sea reflejo del sexo de $\mathrm{J}$ » (40). Además, el tipo de narración que esta «escritora» ofrece es una narración laica, más cercana a la obra de un Tolstoi, de un Dante o de un Freud, quienes, como hace esta hipotética escritora, se encargaron de revisar todos los textos anteriores. Así también la Yahvista revisa los textos que la precedieron, de modo que su ironía literaria depende de obras más ingenuas y directas que la suya: «Sitúo a J y al Historiador de la Corte en el reino de Roboam porque para mí la nostalgia por David, la incertidumbre sobre el esplendor salomónico y un irónico desdén por Roboam y por el pueblo son características del texto de J" (Bloom, 1990: 45).

Pero otra de las particularidades que más llama la atención de de J, es que la escritora se enfrente con David utilizando a José como sustituto, precisamente «a través de la tradición que hace de David, posible abuelo de J, el poeta de los Salmos, tradición que también atribuye la autoría de los Proverbios y el Cantar de los Cantares de Salomón, su posible productor» (49). Que Bloom hable ahora del romance familiar freudiano no es en vano, si tenemos en cuenta que se trata de volver a retomar una vez más un tema que le ha venido obsesionando desde el inicio de su obra: la preocupación por las relaciones entre su «poeta fuerte» con el poeta-padre, precursor en última instancia de su propia obra, de su «poema fuerte». La Yahvista sería entonces la «poeta fuerte» que habría sabido malinterpretar las fuentes precursoras y hacer llegar su voz hasta nuestros días. Aunque esta vez gracias al esfuerzo de Bloom por sacarla a la luz.

\section{Dos judíos universales: Freud y Kafka}

\section{Freud}

Desde que Bloom iniciara su actividad crítica siempre ha confesado sentirse bajo el impacto freudiano. Estaba presente, por ejemplo, en la teoría bloomeana de la ansiedad de la influencia o en la tesis del romance familiar que se establecía a partir de la evolución del efebo en poeta fuerte, como heredero directo del padre-precursor. En la actualidad, y como nos confiesa en uno de sus últimos libros The Anatomy of Influence (2011), Freud no debe ser visto como un científico, sino como uno de los escritores más brillantes de la literatura universal: «La teoría de la mente o el alma de Freud, después de más o menos un siglo, está viva y es valiosa, mientras que su cientifismo está bastante 
muerto» (Bloom, 2011: 30). En verdad, Bloom ha mantenido siempre una relación un tanto ambigua con Freud. Recordemos sus palabras de 1995:

Creo que mis ideas respecto a Freud han variado a través de los años. Incluso hubo un momento en que me propuse escribir un libro sobre él, pero luego deseché el proyecto dado que consideré que mi relación con Freud no era de las más sanas, siempre ha sido muy accidentada (Bracho, 1995:16).

Sin embargo, sí que escribió mucho sobre Freud en sus primeros trabajos, de hecho, dedica algunos de los capítulos más sustanciosos y sugerentes de toda su obra al maestro del psicoanálisis. Recordemos, por ejemplo, el capítulo VI del conocido libro Ruin the Sacred Truths de Bloom con el título «Freud and Beyond». En este trabajo Bloom asegura que la teoría de la represión de Freud es el centro de su vasto proyecto especulativo. Según el crítico de Yale, Freud rechazaba estudiar las nostalgias: «odiaba el pasado y odiaba los Estados Unidos, quizá porque temía que eran el futuro» (Bloom, 1989: 145). A decir de nuestro autor Freud nunca se pudo sustraer de su tradición cuando escribía, aunque siempre lo hacía de una forma selectiva, como todo buen judío; de modo que muchas de sus explicaciones no eran sino simples ambigüedades y especulaciones que no le llevaban a ningún sitio: como si estuvieran siempre en perpetuo exilio, en un continuo vagar errante. Su obsesión por el mito del exilio le llevó a creer que «el psicoanálisis llega a ser otra parábola de la gente sin hogar o al menos sin un sitio fácil de encontrar « (146); y que debe buscar continuamente, casi desesperadamente, hasta el último de sus días. En este sentido, Bloom asegura que la teoría de la represión de Freud sólo es coherente «si se encuentra en un cosmos psíquico donde absolutamente todo está lleno de significado, de modo que un sueño, un chiste, un síntoma o una transferencia pueden sostener un nivel de intensa interpretación» (147).

Obsesiones aparte, Freud conocía perfectamente el papel tan decisivo que tenía su condición de judío en sus descubrimientos, pues sabía que gracias a la importancia de su herencia judía él poseía una gran cualidad: el valor de luchar contra lo que llamaba la «mayoría compacta», casi sin esperanza, solo. Esto era lo que le hacía estar abocado al libre ejercicio de su pensamiento: «subrayando de este modo el carácter específico de su obra, coincidió sin saberlo con el mayor poeta judío contemporáneo, Franz Kafka» (Robert, 1967: 89). Para Bloom, pues, estaría claro que Freud probablemente hubiera admitido que su obra, por original y subversiva que fuera, en cierto modo no era más que un eslabón al final de la antigua tradición judía, es decir, sería - como comenta Robert- «algo así como el último comentario de la Ley» $(90)^{9}$. En este sentido, la idea de que el judío encuentra desde su cuna los medios justos para pensar y para seguir las voces de la razón, entraña para Freud -y para toda la tradición judía- una consecuencia decisiva en la trayectoria de la vida y del pensamiento: si pensar con acierto es más fácil para el judío, para quien no existe el elemento místico; entonces éste tiene también la obligación de luchar contra el error, los prejuicios, las supersticiones y todas las quimeras espirituales que oscurecen la verdad. Esta es efectivamente, en opinión de Bloom, la tarea que Freud se impuso y

\footnotetext{
${ }^{9}$ Para una visión diferente de la relación entre el pensamiento de Freud y su judaísmo véase Derrida, Jacques (1997). Mal de archivo. Una impresión freudiana, Madrid: Trotta.
} 
que cumplió hasta el final, defendiendo sus ideas judías, incluso contra los judíos y el judaísmo, allí donde ellos parecían extraviarse.

Pero a pesar de participar Freud de esa conciencia judía o mejor dicho, de la tradición memorística del pueblo judío, Bloom advierte una cierta relación de ambigüedad entre él y el propio judaísmo, en concreto en lo que concierne al tema de lo sublime: «esa sublimación, en el sentido freudiano, bien puede ser un ideal judío, pero el verdadero centro del trabajo de Freud es su concepto de represión, que es profundamente judío, e incluso normativo» (Bloom, 1989: 152; la traducción es mía).

En opinión de Bloom, una de las más grandes herejías de Freud, desde una perspectiva judía, es su transferencia del tropo hebreo de la paternidad de Yahvé al totémico dios ancestral de la primera horda:

\begin{abstract}
Dios aparece ya tan por encima de los hombres, que éstos no pueden comunicar con él sino por mediación de sus sacerdotes [...]. Observamos, pues, que el padre, restablecido en sus derechos, se venga cruelmente de su antigua derrota elevando a un grado máximo el poder de su autoridad. Los hijos aprovechan estas nuevas circunstancias para eludir aun más su responsabilidad por el crimen cometido. No son ya ellos, en efecto, los responsables del sacrificio; es Dios mismo quien lo exige y lo ordena (Freud, 1993: 1843).
\end{abstract}

De hecho, cuando Freud analiza este tema, lo hace desde su libertad de judío, una libertad del pasado, esa libertad judía que no es sino «una libertad de interpretación, aunque la memoria judía (y freudiana) se sobrevaloren» (Bloom, 1989: 154). Una de las necesidades freudianas más fuertes siempre fue buscar una explicación sobre los orígenes del pensamiento, como si el hecho de pensar fuera un proceso relativamente libre. Como se recordará, existen para Freud dos procesos de la mente: el proceso primario, que continúa en el sistema del inconsciente, y el proceso secundario, que caracteriza el sistema preconsciente. Ambos sistemas fueron vistos por los seguidores de Lacan, los freudianos franceses, como otro camino de describir unos procesos que no son sino dos modos de poesía o figuración o dos formas de «creatividad». Es así, quizá, como el mismo Bloom prefiere estudiar la obra freudiana, de la que asegura que no hay una lectura verdadera o correcta porque Freud es un escritor tan fuerte que contiene cualquier modo posible de interpretación (Bloom, 1982: 92).

Leer a Freud nos enseña que nuestra vida instintiva es agonística y últimamente auto-destructiva y que nuestros momentos más auténticos tienden a ser esos de negación, contracción y represión: «la defensa freudiana más poderosa es la represión, que evoluciona desde una preocupación social (el tabú del incesto) hasta formar parte de nuestro legado biológico» (Bloom, 2011: 30-31).

\title{
Kafka
}

Bloom sitúa a Kafka como uno de los escritores más canónicos de todos los tiempos. La impaciencia, como el mismo Kafka aseguró, es el mayor de los pecados, el que abarca a los otros. Pero es que además es, en opinión de Bloom, uno de los pecados más comunes de los judíos. Como Bloom apunta en numerosas ocasiones, Yahvé no era un Dios paciente, y por ello, quizá Kafka intenta crear un Dios de los judíos más paciente. 
En realidad lo que Kafka llamó «paciencia» no era sino una gnosis, sin embargo, como siempre ha reconocido Bloom: «la espiritualidad de Kafka no ofrece una salvación, y por ello no es un gnóstico» (Bloom, 1989: 167). Lo que Kafka consigue de hecho es llegar un paso más lejos del Gnosticismo, negando que exista esperanza para alguno de nosotros en parte alguna. En cualquier caso, la facticidad o contingencia kafkiana han presidido la idea de una cultura judía más allá del simple judaísmo normativo, como defendía Gershom Scholem, con la diferencia -asegura Bloom- de que Scholem combinó en su teoría el Sionismo y la Cábala, mientras que Kafka transgredió la frontera e implícitamente mantuvo siempre la convicción de que él podría destruir el cielo (Bloom, 1989: 169). De hecho, los cielos encarnan el ego de Kafka (lo que viene a ser una visión freudiana), pero sólo a través de su escritura, y esta idea tiene mucho que ver con la tradición esotérica judía. No obstante, Kafka está muy lejos de ser otro Isaac Luria, capaz de crear otra teoría catastrófica de «los tres estados», como el mismo Scholem pretendió ver.

Tampoco Bloom cree ver en Kafka un continuador de la Teoría cabalística. La doctrina secreta de Kafka, si es que existió alguna vez, sería totalmente imposible de interpretar. Porque, de hecho, él evitó totalmente cualquier interpretación de su obra, lo que significa que «la escritura de Kafka es una evasión de una interpretación perversamente pensada» (171). Esto es, lo que hace Kafka es evitar una interpretación en el sentido de la interpretación judía: «El poder de Kafka de la evasión no es un poder sobre su mismo texto y construye un lado más de la Torá en nuestro tiempo» (172). Tal y como sucede en su texto de El cazador Gracchus, que repite aspectos fundamentales del esoterismo de la tradición judía:

Quién es el patrón.

-El dueño de la barca. Estos patrones son personas excelentes. Solo que no los entiendo. Y no me refiero a su lengua, aunque a menudo tampoco la entiendo. Pero eso es secundario. He aprendido tantos idiomas en el correr de los siglos que podría ser intérprete entre los hombres de la antigüedad y los contemporáneos. Sino lo que no logro comprender son sus razonamientos (Kafka, 1983: 1294).

Es preciso recordar las circunstancias especiales que envolvieron la génesis de la obra kafkiana para poder captar el desgarramiento y la negatividad que la literatura, como apostilla Bloom en muchas ocasiones, provocaba casi a diario en su existencia. Por un lado, escribir podía parecerle el único medio para romper las barreras ficticias suscitadas por las instituciones y, sobre todo, los prejuicios entre los otros y él. Así, Kafka, que se encontraba solo en su misterioso mandato encuentra en la creación su mayor oportunidad de salvación, pues él sabía que si no se podía salvar, al menos podía instruir a los otros, porque en calidad de muerto vivo poseía la mirada más clara, veía otras cosas y más lejanas que la generalidad de los hombres (Robert, 1967: 26). En este sentido era en el que Walter Benjamin entendía la experiencia mística que inspiró a Kafka la elaboración de la mayoría de sus obras, pues siempre defendió que hablar de sus obras solo como un reflejo de un mundo divino era una mera simplificación. Esta tesis se puede comprobar en Preocupaciones de un padre de familia, en el que se nos cuenta la historia de un personaje oscuro que vive con una familia y que se llama Odradek. A lo largo de la lectura del texto no sabemos muy bien si nos encontramos ante una criatura muy pequeña, algo así como un gnomo, o si se trata ciertamente de un demonio que vive en el mundo de los niños: 
Se esconde alternativamente en la buhardilla, en la caja de la escalera, en los corredores, en el vestíbulo. A veces no se lo ve durante meses; suele mudarse a otra casa; pero siempre vuelve fielmente a la nuestra. A menudo, cuando al salir por la puerta uno se lo encuentra apoyado justamente debajo de la escalera, siente deseos de hablarle. Naturalmente, no le hace una pregunta difícil, más bien lo trata -su tamaño lo exige- como a un niño (Kafka, 1983: 1142).

Para el crítico de Yale este texto representa, sin embargo, uno de los casos más desesperados de Kafka, pues la obra aparece bajo la forma absolutamente indescifrable del más ínfimo, del más absurdo de los objetos, al que Kafka llama Odradek. Es una especie de bobina de hilos enredados que, hecha de una materia indefinible y dotada de una especie de vida, responde cuando se le llama por su nombre e incluso es capaz de reír. El relato contiene una alusión muy clara a la tuberculosis de Kafka y otra, más velada, a los sentimientos que Kafka experimentaba respecto a su creación y que, sin duda, le condujeron a condenar, ya que no a destruir personalmente, toda la parte póstuma de su obra (Robert, 1967: 13). La palabra Odradek, palabra completamente imaginaria tiene un doble origen: checo y alemán; y el padre de familia, con el que Kafka puede identificarse aquí describe, por su parte, el objeto familiar y, sin embargo, inasible que asedia su casa y que es en suma «el genio del lugar». Es una bobina plana, en forma de estrella -hecha de filamentos de todos los colores y de todas las cualidades, enlazados en sus extremos y enredados. Odradek anda cojeando y habla. También puede reír, pero su risa es la que se ha dado en llamar el «desafortunado humor de Kafka»: «Domicilio desconocido -dice y ríe; claro que es la risa de alguien que no tiene pulmones. Suena más o menos como el su surro de las hojas caídas» (Kafka, 1983: 1142).

Este pequeño genio no mora en las estancias habitadas de la casa, sino en el granero, en las alturas o también en la escalera, los corredores o el vestíbulo, los lugares comunicados entre sí y con el exterior. Desaparece durante meses, pero siempre vuelve, fiel a todo y a todos. Y es que Odradek, una cosa absurda, sin origen definido, ni fin, ni futuro, parece pertenecer a un espacio intermedio del que la propia muerte está excluida. Y el pensamiento de esta eternidad inspira al padre de familia un melancólico ensueño: «la sospecha de que pueda sobrevivirme me resulta casi dolorosa (Kafka, 1983: 1143).

Como los escritos de su autor, Odradek participa de dos lenguas y se apoya en tres culturas diferentes: la alemana, la checa y la judía (aunque sin reivindicar ninguna). Es un híbrido, hecho de hilos que no conducen a ninguna parte: es la imagen que Kafka se hacía de sus innumerables fragmentos $\mathrm{y}$, de hecho, compone un extraordinario laberinto en el que el hilo conductor parece escaparse constantemente. Odradek es absurdo, inútil, y obtiene parte de su misterio por su naturaleza infantil e inmortal. Así pues y, según comenta Bloom, no es un personaje exclusivamente creado como reflejo divino de un mundo inconmensurable. En opinión de Bloom el personaje Odradek de Kafka tiene mucha similitud con el gólem, aunque el de Kafka parece que fue creado por un niño, porque es un personaje paródico, casi grotesco, con el que el escritor de Praga quiere avisarnos para que no lo interpretemos seriamente. Odradek es inmortal, nos avisa el crítico de Yale, un ser casi demoníaco, que representa también el retorno freudiano de lo reprimido (Bloom, 1989: 177).

Uno se siente inclinado a creer que esta criatura tuvo en otro tiempo alguna especie de forma inteligible, y ahora está rota. Pero esto no parece comprobado; por lo menos, no hay nada que lo demuestre; no se ve ningún agregado o rajadura que corrobore esta suposición; es un conjunto bastante absurdo pero 
dentro de sus estilo, bien definido. De todos modos, no es posible un estudio más minucioso, porque Odradek es extraordinariamente ágil y no se le puede apresar (Kafka, 1983: 1142).

Al Jasidismo ${ }^{10}$ se le debe la figura del Gólem o del Homúnculos mágico, que es «la culminación legendaria de los poderes sobrenaturales logrados por los cabalistas» (Barnatan, 1986: 62), y que vendría a ser en términos más concretos, el Odradek de Kafka que acabamos de conocer. El gólem es una figura ahasverica de la que se dice que se aparece cada treinta y tres años en la ventana de un gheto de Praga. Este gólem es, en parte, un alma colectivizada del gheto «con todos sus residuos de lo fantasmal y, en parte, un doble del héroe, un artista que lucha por su liberación y que purifica mesiánicamente en ella al gólem, su propio yo esclavizado» (Scholem, 1988: 174). Pero además de esta teoría, Scholem recoge también otra sobre los judíos polacos, en la que nos cuenta que ellos modelan, tras un periodo de ayuno, una figura de un hombre de arcilla y cola, y después de pronunciar su nombre divino, el gólem tiene que cobrar vida. Y aunque no puede hablar, entiende bastante de lo que le dicen, generalmente son órdenes, pues utilizan a esta figura de barro como el encargado de realizar las tareas de la casa, de la que nunca debe salir. Día a día, el gólem va engordando y se va haciendo más grande y más fuerte, a pesar de lo pequeño que era cuando lo hicieron. Tiene en la frente escrita la palabra Emet, que quiere decir «verdad». Por eso cuando el gólem se hace casi gigantesco, los habitantes de la casa se atemorizan y le borran la letra 'e' de modo que queda la palabra 'met', que quiere decir «está muerto», y así el gólem cae muerto convertido en un montón de arcilla (174).

Aparte de esta novela, existen dos textos de Kafka que nos permiten de manera más sosegada hablar del retorno del escritor a la memoria cultural judía, se trata de El problema de nuestras leyes y Josefina la cantante o el folklore de los ratones. Lo que su autor pretendió con estos libros no fue conseguir la redención de su alma, como quizá sí lo hicieran otros escritores, por ejemplo, Dante, quien, como confiesa Bloom en muchas ocasiones, tuvo la audacia de entronizar a Beatriz en el paraíso. O Milton que creía en un alma mortal que resucitaría con el cuerpo. No olvidemos, sin embargo, que Kafka es un escritor judío que se evadió de su propia audacia porque él no creía en nada, pues confiaba solo en la conveniencia de ser escritor: «los intelectuales judíos está empujados a darse cuenta de que ellos mismos son el producto de la ruptura con la tradición» (Bloom, 1989: 157).

Por su parte, el relato de La Metamorfosis debe entenderse, en opinión de Bloom, como una narración kafkiana crucial que tiene lugar entre la verdad y el significado. La verdad está en la esperanza y nunca es posible, mientras que el significado está con el futuro o en la edad mesiánica, y tampoco lo podemos conseguir. En este texto la muerte del protagonista, Gregorio, no debe verse como un sacrificio, ni siquiera como una especie de ironía trágica, ya que se trata, como analiza Bloom, de otra negación kafkiana que rechaza negar lo dado:

\footnotetext{
${ }^{10}$ El Jasidismo es una doctrina que surgió en momentos de sentimientos apocalípticos, debido a la inminencia del año 5000 de la era hebrea, y al año 1240 de la cristiana en el que se esperaban sucesos imprevisibles. «Pero el procedimiento básico del jasidismo no era la magia taumatúrgica como la ignorancia hizo creer, sino una ferviente intención de hacer de todos los actos humanos meras sombras del acto supremo de amor a Dios. El jasid, el santo, ofrece su vida al amor por su creador al que necesariamente se somete a cada instante y en cada momento de su existencia. Las riquezas, los poderes y los placeres terrenales no le interesan, su ambición está concentrada en la llegada del tiempo mesiánico, y esa es su más grande ilusión» (Barnatan 1986: 61).
} 


\footnotetext{
Y en tal estado de apacible meditación e insensibilidad permaneció hasta que el reloj de la iglesia dio las tres de la madrugada. Todavía pudo vivir aquel comienzo del alba que despuntaba detrás de los cristales. Luego, a pesar suyo, su cabeza se hundió por completo y su hocico despidió débilmente su postrer aliento (Kafka, 1985: 101).
}

Gregorio se debate entre la verdad y el pasado, o la memoria judía; pues el judaísmo mesiánico no es sino ese significado del futuro (Bloom, 1989: 188). No olvidemos, sin embargo, que frente a esta negación del judaísmo que Bloom propone como lectura de la obra de Kafka, existe el método de escritura de Kafka que se basa en la descripción de fantasías personales que arrancan de una visión indiscutiblemente cotidiana de la existencia. El sentido de la victimización y de la angustia es un sentimiento común a los héroes de los tres grandes relatos de Kafka: El proceso, El castillo y La metamorfosis. Pues a pesar de su laberíntico interior todos ellos traslucen «la pesadilla de lo extraordinario y lo trágico en una atmósfera laberíntica, angustiante y sobrenatural» (Manzano, 1992: $195)$.

La última novela que Bloom analiza del autor del psicoanálisis es El Castillo, porque entiende que el castillo representa también la «Gracia», como ya indicara Brod, en el sentido de que la Gracia es una de las formas bajo las cuales, según la cábala, la divinidad se nos ofrece. Y, en cierto sentido este es «el cuento de cómo Kafka escribe su camino de vuelta al abismo, de la imposibilidad de K. de hacer su trabajo como agrimensor» (Bloom, 1994: 193). Parte de los límites de K. se deben a su poca audacia. De hecho el personaje principal se ve abocado siempre al fracaso porque establece una lucha contra Klamm, que es un ser muy superior a él.

En su búsqueda de lo canónico, de la angustia de la influencia del escritor, de la mala lectura del texto, de la tradición cabalística, del análisis de la Biblia hebrea, de la obra de los judíos Freud y Kafka, en definitiva, de la influencia de la literatura en la vida, el crítico de Yale ha sabido, como ningún otro teórico, dar respuesta a todas las cuestiones que el público moderno se sigue plantando ante la lectura de cualquier obra de indiscutible calidad, la realmente canónica. Como el propio Bloom nos confirma: «a lo largo de toda una vida leyendo y enseñando se aprende tanto de tantos que uno no llega a tener muy claro cuáles son sus deudas intelectuales. Nunca llegaré a conocer a cientos de aquellos a quienes he reeditado, pero me han ayudado a ilustrarme en la medida en que he sido capaz de aprender de alguien que ha sido un huésped de otras mentes» (Bloom, 2005: 15). Amén.

\section{Referencias bibliográficas}

Alter, R. (1994): «Scholem and Modernism», Poetics Today, 15, pp. 429-442.

Álvarez de Morales, C. (1996): Aproximación a la teoría poética de Harold Bloom. Granada, Universidad de Granada.

AsH, B. (1987): «Jewish Hermeneutics and Contemporary Theories of Textuality: Hartman, Bloom, and Derrida», Modern Philology, 85, pp. 65-80

BARNATAN, R. (1986): La Kábala. Una mística del lenguaje. Madrid, Akal.

BARgON, J. (1990): «It’s a Girl!», The New York Review of Books, XXXVII/18, pp. 3-4. 
Bloom, H. (1973): The Anxiety of Influence. A Theory of poetry. London, Oxford University Press. - (1975): A Map of Misreading. Oxford, Oxford University Press. (1982): Agon. Towards a Theory of Revisionism. London, Oxford University Press. (1989): Ruin the Sacred Truths. Poetry and Belief from the Bible to the Present. Cambridge, Massachussets and London, Harvard University Press.

- (1994): The Western Canon. London, Hartcourt Brace and Company.

- (2011): Anatomía de la influencia. La literatura como modo de vida. Madrid, Taurus.

Bloom, H., y Rosenberg, D. (1995): El libro de J. Barcelona, Interzona

Bokser, N. M. (1980): «Talmudic Form Criticism», Journal of Jewish Studies, 31, pp. 46-60.

Boyarin, D. (1987): «Old Wine in New Bottles», Poetics Today, 8, pp. 539-556.

BRACHO, E. (1994): «La lista de Bloom», Quimera, 13, pp. 12-18.

CAÑEQUE, C. (1984): «Harold Bloom o el parricidio de la dialéctica continental», Cuadernos del Norte, 26, pp. 52-60.

Catelli, N. (1991): «Y una mujer creó a Dios», Quimera, 105, pp. 12-18.

DAVIE, D. (1991): «Bloom's Bible», London Review of Books, 13, p. 3.

DERRIDA, J. (1967): Writing and Diference. London, London University Press.

FRYE, N. (1973): La estructura inflexible de la obra literaria. Madrid, Taurus.

FrANK, K. (1983): Obras Completas, vol. III. Barcelona, Teorema.

LAPIDUS, R. (1993): «Halakah and Haggadah: Two Opposing Approaches to Fulfilling the Religious Law», Journal of Jewish Studies, 44, pp. 100-113.

MANZANo, S. (1992): La comunicación epistolar. Análisis semiótico de las cartas de Frank Kafka a Felice Bauer. Madrid, UCM.

Monferrer Sala, J. P. (1998), «El Libro de J» (reseña), Boletín de la Asociación Española de Orientalistas, 34, pp. 430-433.

Robert, M. (1967): Acerca de Kafka. Acerca de Freud. Barcelona, Anagrama.

SCHOLEM, G. (1988): La Cábala y su simbolismo. Buenos Aires, Proyectos Editoriales. 